\title{
Capacity of Landscaping Plants to Accumulate Airborne Particulate Matter in Hangzhou, China
}

\author{
Guo Li ${ }^{1}$, Lihua Wang ${ }^{1}$, Fengbin Sun ${ }^{2}$, Yujie Wang ${ }^{1}$, Haitang Wu${ }^{1}$, Zewei Hu${ }^{1}$, \\ Binbin Zhang', Lu Yu', Hai Yan', Feng Shao ${ }^{1,3 *}$ \\ ${ }^{1}$ School of Landscape Architecture, Zhejiang Agriculture and Forestry University, Hangzhou, China \\ ${ }^{2}$ School of Agriculture, Heilongjiang Bayi Agricultural University, Daqing, China \\ ${ }^{3}$ School of Landscape Architecture, Beijing Forestry University, Beijing, China
}

Received: 18 August 2018

Accepted: 15 December 2018

\begin{abstract}
Plants have a great capacity to absorb airborne particulate matter (PM), which can be used to improve air quality in severely polluted regions. We selected eight common landscaping plants in Hangzhou, China, and determined the different-sized PM adsorption capacities of their leaf surfaces and wax layers using gravimetric analysis. In addition, we used scanning electron microscopy to observe surface microstructures of the leaves to determine relationships between their microstructural characteristics and adsorption capacities. Results showed that the capacity of these eight species to accumulate PM varied markedly, showing obvious differences in particle retention between trees and shrubs. The densities of PM per unit leaf area of the various plants ranged from $12.4 \mu \mathrm{g} / \mathrm{cm}^{2}$ to $151.8 \mu \mathrm{g} / \mathrm{cm}^{2}$, with Fatsia japonica $>$ Ilex latifolia $>$ Eriobotrya japonica $>$ Magnolia grandiflora $>$ Rhododendron pulchrum $>$ Cinnamomum camphora $>$ Trifolium repens $>$ Albizia julibrissin. There was a close relationship between surface microstructures of the leaves and their PM adsorption capacities: the rougher the leaf surface and the greater the furrow depth, the better their capacity for PM adsorption, resulting in a greater dustretention capacity. Clearly, understanding retention of PM on different plants can aid in the selection of landscaping plants to reduce urban air pollution.
\end{abstract}

Keywords: PM, landscaping plants, dust-retention capacity, gravimetric analysis, leaf surfaces microstructure

\section{Introduction}

With the development of society, air pollution has become increasingly serious, with particulate matter (PM) being one of the major pollutants in the atmosphere. Fine particulate matter $\left(\mathrm{PM}_{25}\right.$, with diameters less

*e-mail: shaofeng79@sina.com than or equal to $2.5 \mu \mathrm{m}$ ) has the greatest potential to affect human health [1-2], because its small particle size allows it to enter the alveoli of the lungs. Typically, it is not only rich in poisonous and harmful substances, but has a long residence time in the atmosphere and can be conveyed long distances, contributing to human health issues, poor visibility, and poor air quality in urban environments [3-5]. Although it comprises only a few components, it can contain polycyclic aromatic hydrocarbons (PAHs), which are 
carcinogens with long-term toxicity and teratogenicity [6]. Numerous studies have shown that $\mathrm{PM}_{25}$ has acute and chronic health effects, and that high $\mathrm{PM}_{2.5}$ exposure increases the risks of acute respiratory and cardiovascular diseases [7-8].

There are numerous national and international research reports on the adsorption of airborne PM by plants, with large experimental datasets showing that plants accumulate PM and improve air quality through the accumulation of PM on leaf surfaces and in wax layers [9-11]. In Poland, Dzierżanowski et al. (2011) concluded that different plants have different PM adsorption capacities, but all plants accumulate PM [12]. Zhao et al. (2015) also showed that landscaping plants have the capacity to adsorb enough airborne PM to improve air quality [13]. Furthermore, researchers have found that leaves can adsorb volatile organic compounds in the atmosphere, such as PAHs [14-15]. Typically, the dust-retention capacity of different kinds of plants varies markedly [16-18]. Studies have shown that the capacity of plants to capture PM is related to growth form, whereby trees best accumulate both coarse and fine PM [19-20]. The microstructures and morphology of the leaf surfaces also influence the adsorption of PM, reflecting roughness, gaps on the leaf surface, distribution of pores, and mucus secretion. Thus, different plants have variable dust-retention capacities [21-23].

At present, although many studies have analyzed and measured the PM adsorption capacities of plants [24-25], few experiments have quantitatively evaluated their impact on air pollution. This paper measured different sizes of PM to compare the adsorption capacity of different plants and provide a species reference for urban landscape architects.

\section{Materials and Methods}

\section{Sample Selection and Collection}

Sampling was carried out on the campus of Zhejiang Agriculture and Forestry University, Lin'an district, Hangzhou, China (N30 26'28', E119 $\left.{ }^{\circ} 73^{\prime} 47^{\prime \prime}\right)$ (Fig. 1). The campus is about $2.5 \mathrm{~km}$ from the main urban center and far from industrial districts. Covering a total area of about $146 \mathrm{hm}^{2}$, the campus has a gentle topography, surrounded by hills on three sides. It has a large artificial lake. On campus, the ecological environment is good, supporting more than 3000 plants.

In this experiment, we selected eight common landscaping plants as research objects, including five trees, two shrubs and one herb (Table 1). Plant leaves were collected from Cinnamomum camphora, Albizia julibrissin, Fatsia japonica, Ilex latifolia, Trifolium repens, Magnolia grandiflora, Eriobotrya japonica and Rhododendron pulchrum on campus on 25 April 2017, under the same environmental conditions. Given that weather conditions (wind speed and rainfall) can affect PM adsorption on plant leaves [26], we collected samples following a week-long period with no rainfall or strong winds. On the day of collection, the weather was fine and wind speed was less than $5 \mathrm{~m} / \mathrm{s}$. New leaves selected from plants were healthy, with no obvious signs of plant diseases or insect pests. Plant leaves of species having the same growth form were collected at the same height from all aspects to ensure no directional bias to samples. To address the gradient change of the canopy in the vertical direction, upper, middle and lower parts of the crown were sampled at multiple points to avoid variable influences of wind and other external environmental parameters on the leaves

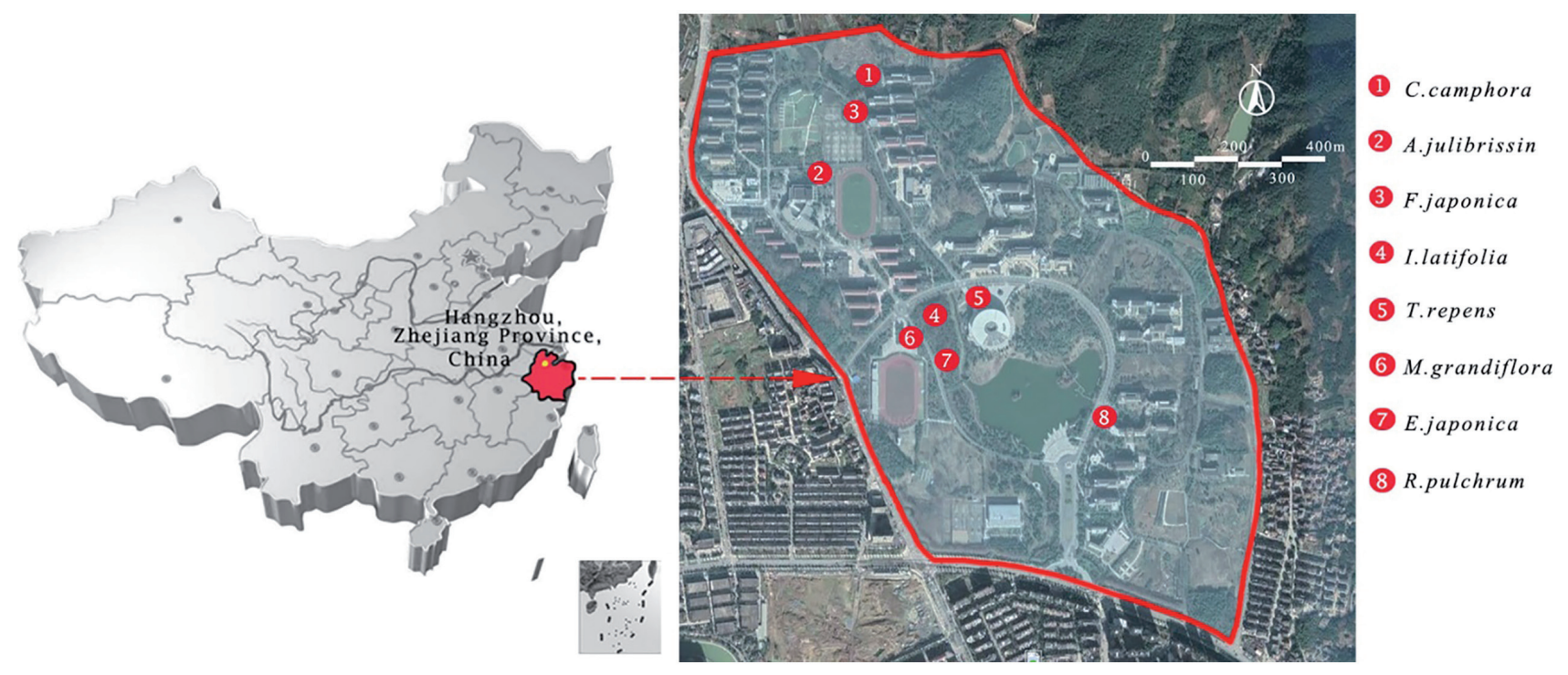

Fig. 1. Sampling sites of selected plants at Zhejiang Agriculture and Forestry University, Hangzhou, China. 
Table 1. List of landscaping plants analyzed in this study.

\begin{tabular}{|c|c|c|c|}
\hline Classification & Species & Life form & Family \\
\hline \multirow{4}{*}{ Trees } & Cinnamomum camphora (L.) Presl & Evergreen & Lauraceae \\
\cline { 2 - 4 } & Eriobotrya japonica (Thunb.) Lindl. & Evergreen & Rosaceae \\
\cline { 2 - 4 } & Ilex latifolia Thunb. & Evergreen & Aquifoliaceae \\
\cline { 2 - 4 } & Magnolia grandiflora L. & Evergreen & Magnoliaceae \\
\cline { 2 - 4 } & Albizia julibrissin Durazz. & Deciduous tree & Araliaceae \\
\hline \multirow{2}{*}{ Shrubs } & Fatsia japonica (Thunb.) Decne. et Planch. & Evergreen & Ericaceae \\
\cline { 2 - 4 } & Rhododendron pulchrum Sweet. & Semi-evergreen & Leguminosae \\
\hline
\end{tabular}

facing different directions. The experimenter wore rubber gloves while sampling and collected an area of about $100 \mathrm{~cm}^{2}$ per sample. After collection, leaves were placed in a sample bag, which was labeled and sealed immediately. Analyses were carried out on the same day. To reduce dust loss from leaves, sample bags were handled with care.

\section{Methods}

\section{Measurement of the Mass of Particulate Matter per Unit Leaf Area}

We used gravimetric analysis to measure the mass of PM on the leaf surfaces and in the wax layers of eight plants in this study. Three different types of membrane filters (Merck Millipore Ltd., Merck, Ireland) were used, measuring particle fractions with diameters of 0.2-2.5 $\mu \mathrm{m}$ (finest fraction), 2.5-10 $\mu \mathrm{m}$ (coarse fraction) and $>10 \mu \mathrm{m}$ (largest fraction). Before filtration, the membrane filters were weighed with a scale (SI-234; Denver Instrument Inc., Bohemia, NY, USA). They were placed in an artificial weather box (Premium ICH; Snijders Industriële Verpakkingen BV, The Netherlands) for $24 \mathrm{~h}$ under conditions of constant temperature and relative humidity $\left(25^{\circ} \mathrm{C}, 40 \%\right)$, and were weighed upon removal. The external environment was stable while weighing to avoid any increase in the filter's weight caused by moisture in the air. All leaves were placed into a triangular beaker for filtering, in which particles on the leaf surfaces and in the wax layers were removed by adding deionized water and then chloroform, successively. The aqueous solution within the triangular beaker was placed in a constant temperature oscillator (HZQ-X300C; Shanghai Yiheng Scientific Instrument Co., Ltd., China) for $10 \mathrm{~min}$, then successively run through a corrosion-resistant vacuum filter (SHB-IIIA; Hangzhou David Scientific Instrument Co., Ltd., China) using all three different sizes of membrane filters. In the chloroform step, this process was carried out in the fume cupboard because of its toxicity. In this case, the oscillation process was carried out for less than $1 \mathrm{~min}$. After filtering, we put all membrane filters in an oven (XMTD-8222; Shanghai Jinghong Experimental Equipment Co., Ltd., China) for $30 \mathrm{~min}\left(60^{\circ} \mathrm{C}\right)$, and then into the artificial weather box for $24 \mathrm{~h}\left(25^{\circ} \mathrm{C}, 40 \%\right)$, before weighing them again. Finally, we calculated the mass differences for both the leaf surface and the wax layer extractions for each plant, yielding their adsorbed PM masses, respectively.

The leaves in the triangle beaker were washed clean and air-dried, and the area of the blades was measured using a portable leaf area meter (LI-3000C; LI-COR Biosciences Inc., Lincoln, NE, USA). The total leaf area of each plant was obtained by adding the areas of all individual leaves. In this way, the densities of PM per square centimeter of the leaf surface and wax layer of each plant could be calculated.

\section{Microscopic Leaf Surface Observations}

The collected leaves were placed in an oven at $60^{\circ} \mathrm{C}$ for $48 \mathrm{~h}$ until the leaves were completely dry. One section $\left(5 \times 5 \mathrm{~mm}^{2}\right)$ was cut from a dried leaf of each species to examine the adaxial surface. This square leaf section was glued onto a sample stage with conductive adhesive and then sputter-coated with gold using an ion sputter coater (E-1045; Hitachi Co., Ltd., Tokyo, Japan). Using SEM (S-3400N; Hitachi Co., Ltd., Tokyo, Japan), we observed the surface morphology of the leaf section as well as the shapes of any adsorbed PM. Images were adjusted to appropriate magnifications for photography. At least three images were taken of each leaf section.

\section{Data Analysis}

Statistical analysis and data compilation were carried out using Microsoft Office Excel (Microsoft Corp., Albuquerque, NM, USA), while SPSS18.0 (SPSS Inc., Armonk, NY, USA) was used for variance analysis and statistical tests. One-way analysis of variance was applied to compare significant differences. Plotting with Origin 7.5 (OriginLab Corp., Northampton, MA, USA). 


\section{Results and Discussion}

\section{Differential Analysis of the Dust-Retention Capacities of Leaf Surfaces and Wax Layers of Various Plants}

The adsorption abilities of different landscaping plants varied greatly for different-sized PM, and was closely related to their growth form. Fig. 2 shows the average densities of accumulated particles on the leaf surfaces and in the wax layers of plants of all three growth forms. The dust-retention of leaf surfaces $\left(17.44 \mu \mathrm{g} / \mathrm{cm}^{2}\right)$ and wax layers $\left(18.22 \mu \mathrm{g} / \mathrm{cm}^{2}\right)$ of trees did not vary markedly, while leaf surfaces of shrubs and the herb had significantly greater PM levels than their wax layers. The densities of dust accumulated on the leaf surfaces and in the wax layers of shrubs were $73.1 \mu \mathrm{g} / \mathrm{cm}^{2}$ and $16.85 \mu \mathrm{g} / \mathrm{cm}^{2}$, respectively. In the case of the herb, they were $14.6 \mu \mathrm{g} / \mathrm{cm}^{2}$ and $3.5 \mu \mathrm{g} / \mathrm{cm}^{2}$, respectively. The densities of dust accumulated on the leaf surfaces of trees and the herb were similar, while the leaf surfaces of shrubs had the highest density of PM. In contrast, the densities of adsorbed PM in the wax layers of trees and shrubs were similar, and were much greater than the PM density in the herb wax layer. Given that trees are generally tall with luxuriant foliage, particles are more easily attached to leaves under windy conditions; they can then penetrate the wax layers of the leaves, making the accumulated PM more stable and difficult to dislodge. Therefore, PM is less likely to be resuspended from tree leaves under the influence of various meteorological factors. Low shrubs are greatly influenced by dust raised by pedestrians, causing the leaf surfaces to adsorb more particles, although only some of the particles penetrate the wax layers of their leaves. In contrast to trees, the dust on shrubs is susceptible to resuspension under the influence of external factors, such as strong winds, rain or snow. Herbs are close to

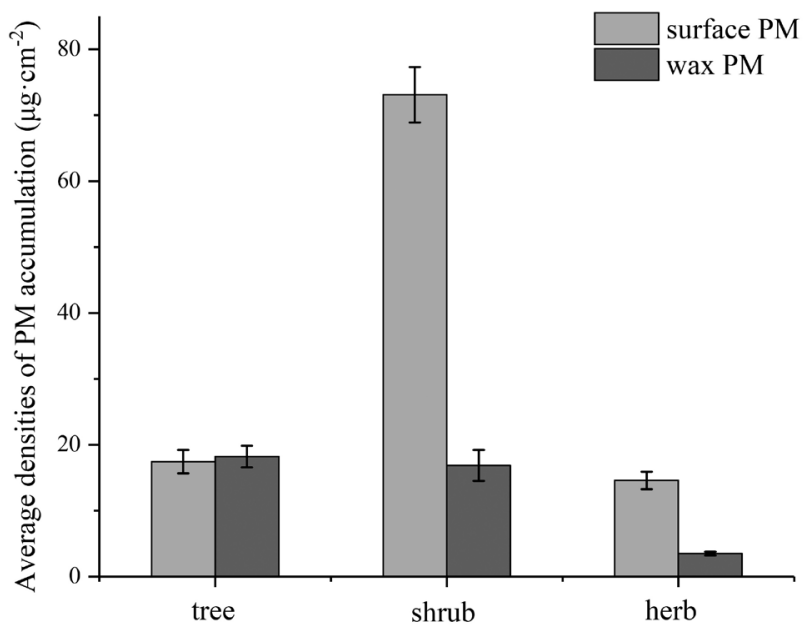

Fig. 2. Particulate matter (PM) accumulation on leaf surfaces and in wax layers of plants with different growth forms (tree, shrub and herb). the ground, making them highly susceptible to raised dust, but because their leaves are tiny and narrow, most particles only briefly remain on the leaf surfaces and do not enter their wax layers. Herb leaves are most affected by external environmental factors. Our data show the importance of various growth forms in landscape design for PM mitigation. Clearly, we need to implement multilayered plant community structures, incorporating trees, shrubs and herbs into urban environments in order to mitigate various PM types.

\section{Differential Analysis of Different-Sized Particulate Matter Accumulation Capacities of Leaf Surfaces and Wax Layers of Various Plants}

Fig. 3 represents the average densities of the three particle size fractions on leaf surfaces of plants with different growth forms. The leaf surfaces of shrubs $\left(69.3 \mu \mathrm{g} / \mathrm{cm}^{2}\right)$ accumulated more large PM compared with trees and the herb; trees and the herb had PM densities of $12.78 \mu \mathrm{g} / \mathrm{cm}^{2}$ and $12.0 \mu \mathrm{g} / \mathrm{cm}^{2}$ on their leaf surfaces, respectively. In the case of the coarse PM fraction, the adsorption capacity of trees $\left(2.9 \mu \mathrm{g} / \mathrm{cm}^{2}\right)$ was highest, with shrubs and the herb having similar capacities of $1.5 \mu \mathrm{g} / \mathrm{cm}^{2}$ and $1.2 \mu \mathrm{g} / \mathrm{cm}^{2}$, respectively. Meanwhile, the adsorption of the fine PM showed little difference among trees, shrubs and the herb, with densities of $1.76 \mu \mathrm{g} / \mathrm{cm}^{2}, 2.3 \mu \mathrm{g} / \mathrm{cm}^{2}$ and $1.3 \mu \mathrm{g} / \mathrm{cm}^{2}$, respectively. Fig. 4 represents the average densities of the three particle size fractions extracted from the wax layers of the plants with different growth forms. The wax layers of shrubs adsorbed more of both the large PM (9.95 $\left.\mu \mathrm{g} / \mathrm{cm}^{2}\right)$ and fine PM $\left(3.1 \mu \mathrm{g} / \mathrm{cm}^{2}\right)$, compared with trees and the herb. The wax layers of trees accumulated most coarse PM $\left(11.68 \mu \mathrm{g} / \mathrm{cm}^{2}\right)$. The herb's adsorption capacities for both coarse and fine PM were weak, yielding densities of $0.6 \mu \mathrm{g} / \mathrm{cm}^{2}$ and $0.2 \mu \mathrm{g} / \mathrm{cm}^{2}$ respectively.

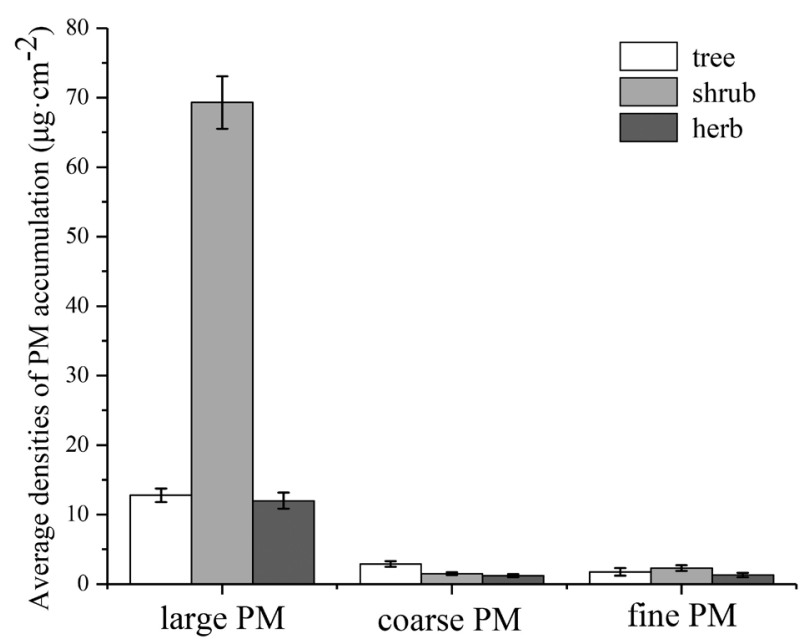

Fig. 3. Particulate matter (PM) accumulation (large, coarse and fine) on the leaf surfaces of plants with different growth forms (tree, shrub and herb). 


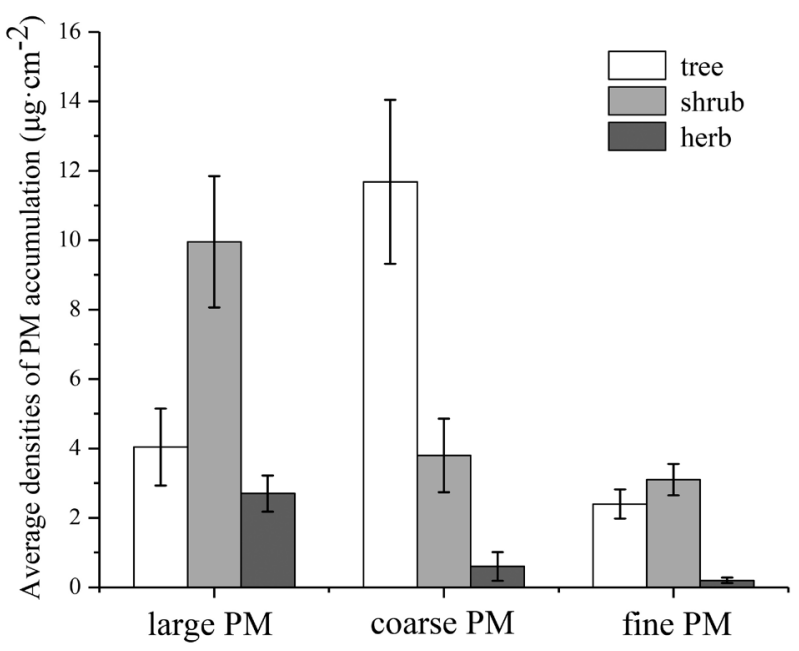

Fig. 4. Particulate matter (PM) accumulation (large, coarse and fine) in the wax layers of plants with different growth forms (tree, shrub and herb).

The height of landscaping plants is clearly a factor that affects their accumulation of PM, because the adsorption of PM mainly occurs via atmospheric particle precipitation. The average leaf height of trees is higher than that of shrubs, and markedly higher than that of ground herbs. Thus, when the wind speed is sufficient to loft particles, plants having wide leaves exposed to the wind will adsorb more PM. Thus, broad-leafed tree species were most effective at dust capture among the plant types studied. Because shrubs and herbs are closer to the ground, their leaf surfaces accumulate more large PM entrained in surface currents or raised by pedestrians.

Clearly, different plants have different adsorption capacities for different-sized PM. It is likely that the movement mode of airborne particles affected the adsorption capacity of leaves at various heights. The wettability of leaves and the microclimate of cultivated land also affect PM adsorption capacities [27]. In windy and dry weather after rain, particles washed out by rain can be resuspended onto leaves. The capacity of the plants' wax layers to adsorb particulates also reflects the amount of wax or mucous on the leaves.

\section{Analysis of the Mass of Particulate Matter Adsorbed by Leaves of Different Plants}

Figs 5 and 6 show the adsorption capacities of the eight plants' leaf surfaces and wax layers for the three size fractions of PM studied. The leaf surfaces of $E$. japonica $\left(33.2 \mu \mathrm{g} / \mathrm{cm}^{2}\right)$ and F. japonica $\left(127.3 \mu \mathrm{g} / \mathrm{cm}^{2}\right)$ had the highest adsorption capacities for PM, while the accumulation of PM on the leaf surfaces of $A$. julibrissin $\left(6.4 \mu \mathrm{g} / \mathrm{cm}^{2}\right)$ was the lowest. The average density of PM accumulated on the leaf surfaces of all eight plants was $31.0 \mu \mathrm{g} / \mathrm{cm}^{2}$. The wax layers of evergreen plants $\left(8.8-47.0 \mu \mathrm{g} / \mathrm{cm}^{2}\right)$ were capable of strong adsorption of PM, with the highest densities recorded

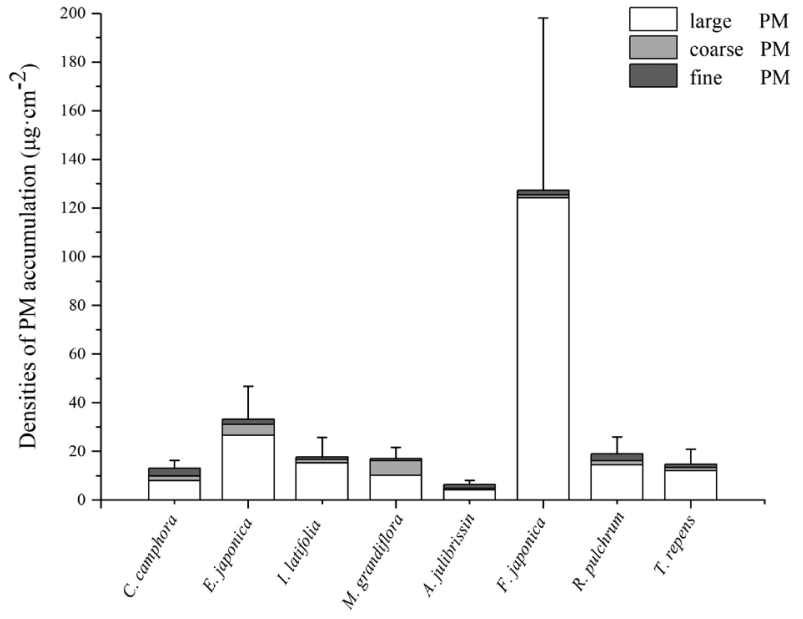

Fig. 5. Particulate matter (PM) accumulation (large, coarse and fine) on the leaf surfaces of eight different plant species.

for I. latifolia, with a value of $47.0 \mu \mathrm{g} / \mathrm{cm}^{2}$. Deciduous plants were shown weaker capacities, with a PM density for $T$. repens of only $3.5 \mu \mathrm{g} / \mathrm{cm}^{2}$. The leaf surfaces and wax layers of $F$. japonica had highest PM adsorption capacities, with values of $127.3 \mu \mathrm{g} / \mathrm{cm}^{2}$ and $24.5 \mu \mathrm{g} / \mathrm{cm}^{2}$, respectively. This is because shrubs play a role in trapping suspended soil dust, preventing it from lofting into the atmosphere. The densities of PM adsorbed on the leaf surfaces and wax layers of the deciduous species A. julibrissin were both low. This is because its spring leaves are small and soft, making them more likely to be affected by wind and other external factors, and inhibiting their adsorption of PM.

Plants with the highest and lowest capacities to adsorb large $\mathrm{PM}$ on their leaf surfaces were $F$. japonica $\left(124.2 \mu \mathrm{g} / \mathrm{cm}^{2}\right)$ and A. julibrissin $\left(4.0 \mu \mathrm{g} / \mathrm{cm}^{2}\right)$, respectively. The capacities of the other six plants were similar, yielding an average density of accumulated large PM for all plants of $26.8 \mu \mathrm{g} / \mathrm{cm}^{2}$.

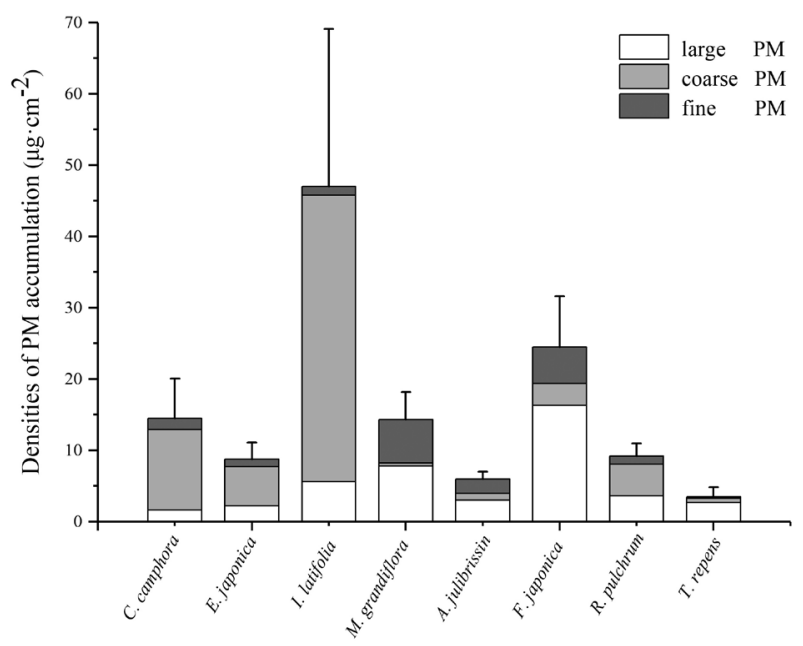

Fig. 6. Particulate matter (PM) accumulation (large, coarse and fine) in the wax layers of eight different plant species. 
The retention abilities of coarse PM on the leaf surfaces of $M$. grandiflora $\left(6.1 \mu \mathrm{g} / \mathrm{cm}^{2}\right)$ and $E$. japonica $\left(4.4 \mu \mathrm{g} / \mathrm{cm}^{2}\right)$ were greatest. In contrast, the adsorption of fine PM on the leaf surfaces showed the least variation among plant species, with the highest and lowest capacities recorded for C. camphora $\left(3.2 \mu \mathrm{g} / \mathrm{cm}^{2}\right)$ and $M$. grandiflora $\left(0.8 \mu \mathrm{g} / \mathrm{cm}^{2}\right)$, and an average density of accumulated fine PM for all eight plants of $1.8 \mu \mathrm{g} / \mathrm{cm}^{2}$. The plant with the highest capacity to adsorb large PM in the wax layers was $F$. japonica $\left(16.3 \mu \mathrm{g} / \mathrm{cm}^{2}\right)$ and the weakest was $C$. camphora $\left(1.6 \mu \mathrm{g} / \mathrm{cm}^{2}\right)$. The plant with the highest capacity to adsorb coarse PM in the wax layers was I. latifolia $\left(40.2 \mu \mathrm{g} / \mathrm{cm}^{2}\right)$, and the weakest adsorption was recorded for $M$. grandiflora and T. repens, with densities of only $0.4 \mu \mathrm{g} / \mathrm{cm}^{2}$ and $0.6 \mu \mathrm{g} / \mathrm{cm}^{2}$, respectively. Adsorption of fine PM in the wax layers showed the least variation among plant species, with an average density of $2.3 \mu \mathrm{g} / \mathrm{cm}^{2}$. Highest densities were recorded for $M$. grandiflora and $F$. japonica, with values of $6.1 \mu \mathrm{g} / \mathrm{cm}^{2}$ and $5.1 \mu \mathrm{g} / \mathrm{cm}^{2}$, respectively. Thus, the dust-retention ability of the leaves of all plants was: $F$. japonica $>I$. latifolia $>$ E. japonica $>M$. grandiflora $>$ R. pulchrum $>$ C. camphora $>$ T. repens $>$ A. julibrissin (Fig. 7).

The ratio between the PM in the wax layers and the total PM showed significant differences among the eight different plants (Fig. 8), with the average ratio being $39 \%$. The plants with the highest and lowest ratios were I. latifolia (73\%) and $F$. japonica (16\%), respectively. Among these plants, the ratios for $C$. camphora, I. latifolia, M. grandiflora and A. julibrissin were all close to or greater than $50 \%$. Clearly, the wax layers play an important role in PM adsorption, resulting in plants with thick wax layers being more effective in accumulating atmospheric particles.

One-way analysis of variance was carried out on the accumulation of PM on leaf surfaces. This analysis showed that there were no significant differences between densities of large and coarse PM fractions on leaf surfaces. Likewise, only slight non-significant differences were observed between densities of coarse and fine PM, and between large and fine PM fractions. In the case of PM in the wax layers, our analysis showed that there were no significant differences in the adsorption capacities of these plants for any size fraction of PM. Neither did the total density of PM adsorbed by these eight plants vary significantly (Table 2). These results differ from results of the experiment of Xie et al. [28] in Beijing but are consistent with experimental results of Sæbø et al. [23]. Wang et al. (2015) studied dust retention on plant species in the Tianjin Airport area; they concluded that the dust accumulated per unit leaf area in shrubs was higher than that of trees [29], which is consistent with our conclusions. Zhang et al. (2013) studied the dust-retention ability of 20 greening plants in Nanjing of Jiangsu. They concluded that dust accumulated by shrubs was slightly higher than for evergreen trees but

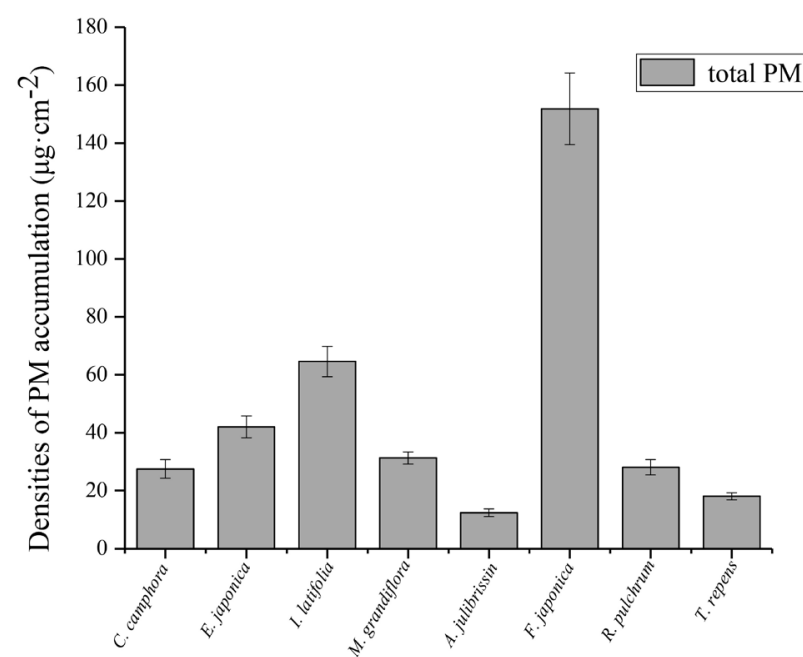

Fig. 7. Densities of particulate matter (PM) accumulated by eight different plant species.

much higher than for deciduous trees. In their study, $M$. grandiflora and $F$. japonica had the highest dustretention capacities [30]. These conclusions support our findings, in which $F$. japonica showed the highest dust-retention capacity, followed by $M$. grandiflora. Gao (2016) studied the dust-retention of typical landscaping plants in Nanning of Guangxi. They concluded that the dust-retention ability of $C$. camphora was greater than both I. latifolia and $R$. pulchrum [31], contrary to the findings of this paper. Such differences likely reflect differences in regional setting and sampling locations.

\section{Analysis of the Effects of Leaf-Surface Microstructures on Dust-Retention}

The microstructures of leaf surfaces have a great influence on the capacity of plants to accumulate PM [32]. To visualize the effects of different leaf microstructures on the adsorption capacity for PM,

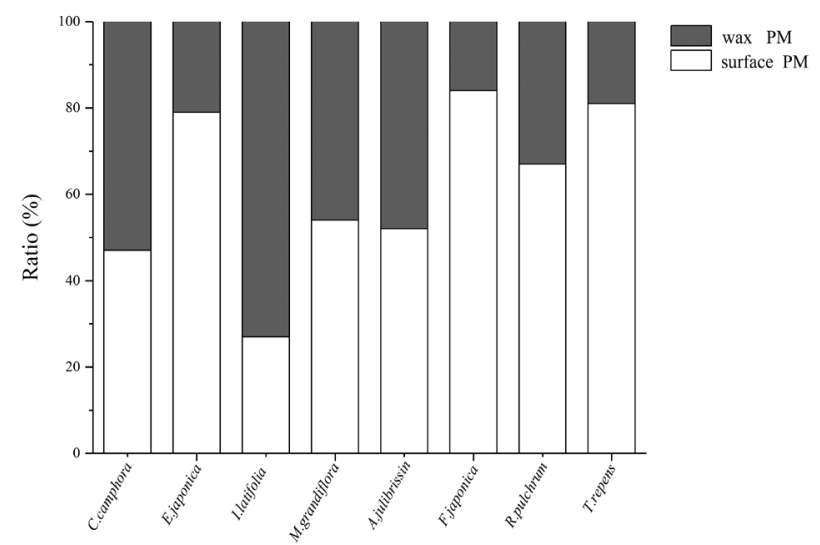

Fig. 8. Ratios between the mass of particulate matter (PM) accumulated by the wax layers versus total PM adsorbed by the leaves of eight different plant species. 
Table 2. One-way analysis of variance showing the accumulation of different-sized particulate matter (PM) on the leaves of plants having different growth forms (tree, shrub and herb).

\begin{tabular}{|c|c|c|c|c|c|c|c|c|c|}
\hline & \multirow{2}{*}{ Classification } & \multicolumn{2}{|c|}{ Total PM } & \multicolumn{2}{|c|}{ Large PM } & \multicolumn{2}{|c|}{ Coarse PM } & \multicolumn{2}{|c|}{ Fine PM } \\
\hline & & $\begin{array}{c}\text { Mean } \\
\left(\mu \mathrm{g} / \mathrm{cm}^{2}\right)\end{array}$ & Sig. & $\begin{array}{c}\text { Mean } \\
\left(\mu \mathrm{g} / \mathrm{cm}^{2}\right)\end{array}$ & Sig. & $\begin{array}{c}\text { Mean } \\
\left(\mu \mathrm{g} / \mathrm{cm}^{2}\right)\end{array}$ & Sig. & $\begin{array}{c}\text { Mean } \\
\left(\mu \mathrm{g} / \mathrm{cm}^{2}\right)\end{array}$ & Sig. \\
\hline \multirow{3}{*}{$\begin{array}{c}\text { Leaf } \\
\text { surfaces }\end{array}$} & Tree & 17.44 & \multirow{3}{*}{0.193} & 12.78 & \multirow{3}{*}{0.243} & 2.90 & \multirow{3}{*}{0.639} & 1.76 & \multirow{3}{*}{0.667} \\
\hline & Shrub & 73.10 & & 69.30 & & 1.50 & & 2.30 & \\
\hline & Herb & 14.60 & & 12.00 & & 1.30 & & 1.30 & \\
\hline \multirow{3}{*}{$\begin{array}{l}\text { Wax } \\
\text { layers }\end{array}$} & Tree & 18.12 & \multirow{3}{*}{0.707} & 4.04 & \multirow{3}{*}{0.341} & 11.68 & \multirow{3}{*}{0.715} & 2.40 & \multirow{3}{*}{0.603} \\
\hline & Shrub & 16.85 & & 9.95 & & 3.80 & & 3.10 & \\
\hline & Herb & 3.50 & & 2.70 & & 0.60 & & 0.20 & \\
\hline
\end{tabular}

selected leaf blades from all eight plant species were observed at $1000 \times$ magnification under SEM (Fig. 9).

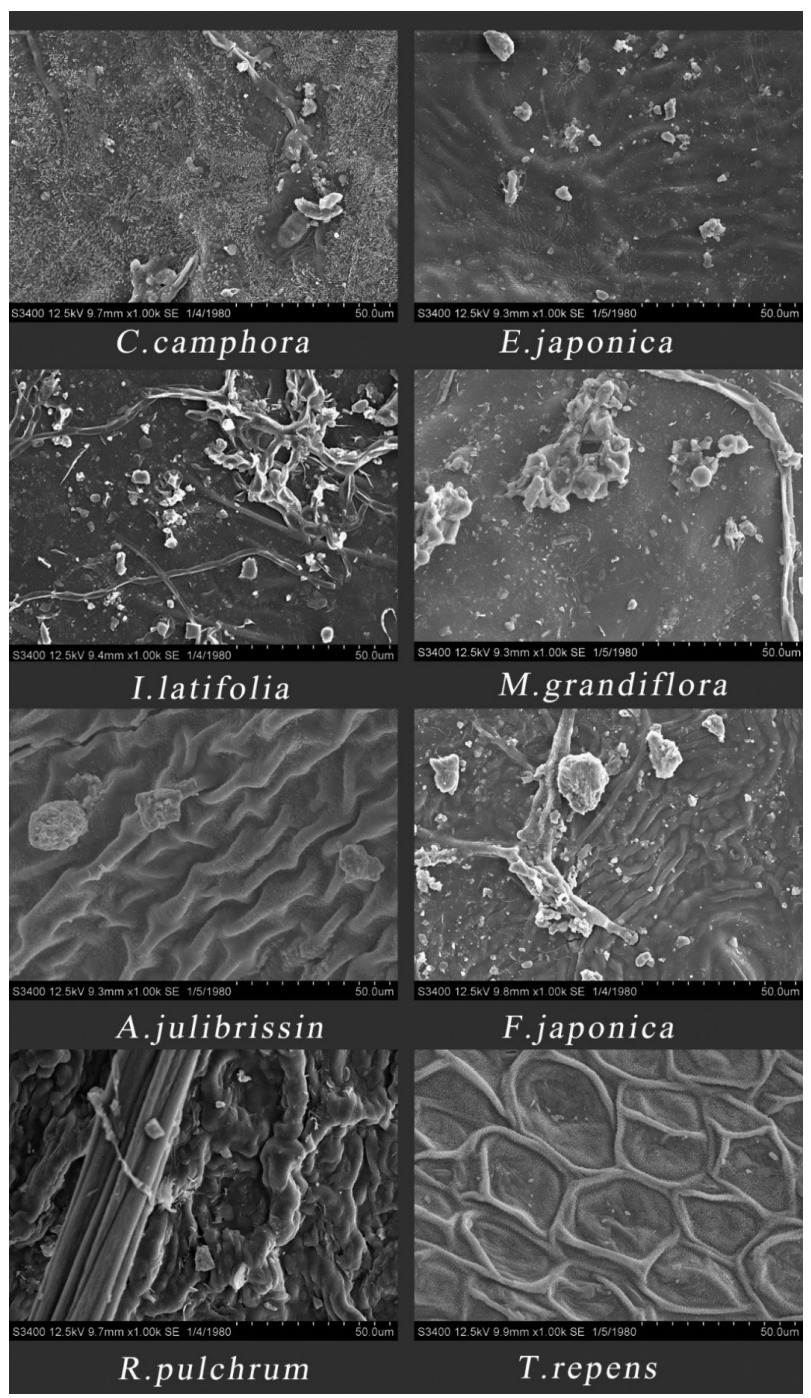

$1000 \times$ magnification

Fig. 9. Scanning electron microscopy images showing the microstructures and adsorbed particulate matter (PM) on the leaf surfaces of eight different plant species.
Images clearly show differences in abundance and types of particles accumulated by different plants.

The comprehensive dust-retention capacity of plant leaf surfaces is influenced by various leaf traits, including tomentum density, stoma density, degree of fold, blade shape, the degree of hardness or softness, leaf area, and leaf angle. If the leaves have certain microstructures, like rough surfaces, tomentum, grooves, raised folds and mucus, then they can accumulate more particles. The evergreen shrub $F$. japonica has large leaf blades with hollow fissures conducive to adsorbing PM from the air as well as dust raised from the ground. Plants with broad, flat, and stiff leaves also adsorb PM more easily than plants with drooping or soft leaves. For example, the leaves of $C$. camphora are smooth and soft, allowing some of the dust adsorbed to slide off the leaf surfaces. In contrast, the leaves of $M$. grandiflora are broad and stiff, with lots of tomenta; these characteristics increase its capacity to accumulate PM [33].

\section{Conclusions}

Both the leaf surfaces and the wax layers of eight species of landscaping plants adsorbed various amounts of atmospheric particulate matter of different sizes. Typically, the surfaces of the leaf blades accumulated more large PM, while wax layers accumulated more coarse PM fractions. Clearly, the microstructures of the leaf surfaces affected the capacity of dust-retention in each species. Plants with rough blade surfaces, having deep folds or gullies, heavy wax layers, villi or mucus, accumulated more PM, yielding a higher dust-retention capacity.

The dust-retention capacities of various plants were obviously different. The most efficient adsorption of PM was by $F$. japonica $\left(151.8 \mu \mathrm{g} / \mathrm{cm}^{2}\right)$, while the least efficient was by $A$. julibrissin $\left(12.4 \mu \mathrm{g} / \mathrm{cm}^{2}\right)$. The density of dust accumulated by $F$. japonica was 12 times more than that of A. julibrissin, while the density accumulated by I. latifolia was 3 times more than that of T. repens. The ranking of the fine PM retention capacities of the eight species studied herein was: F. japonica 
$>$. grandiflora $>C$. camphora $>R$. pulchrum $>$ A. julibrissin $>$ E. japonica $>$ I. latifolia $>$ T. repens. The ranking of the total density of accumulated particles was: $F$. japonica $>$ I. latifolia $>$ E. japonica $>M$. grandiflora $>R$. pulchrum $>C$. camphora $>T$. repens $>$ A. julibrissin. Therefore, the species that adsorbed the most particles was the shrub $F$. japonica; while the trees that adsorbed most particles were I. latifolia and E. japonica. These plants are all common landscaping species in southern China, which could be used widely in greening projects to reduce PM pollution in urban areas.

At present, few studies have documented the PM adsorption capacities of plants for different particle sizes. This study determined the adsorption capacity of leaf surfaces and wax layers for different-sized particles in eight common landscaping plants in southern China. Because particles aggregate on the leaves, the capacity of different plants to adsorb PM of different sizes was determined for large, coarse and fine size fractions. Such information will help landscape architects select plants with the most effective dust-retention capacities for various dust types and PM pollution conditions. Because we only selected young spring leaves in our experiment in Hangzhou, our results only reflect the dust-retention capacity of plants during a limited growth period. In future experiments, we plan to study the leaf adsorption of PM throughout the growing season. By studying the difference in dust-retention capacities of plants for different size fractions, the ecological functions of these plants can be fully utilized to mitigate urban air pollution.

\section{Acknowledgements}

This work was supported by the Project of National Natural Science Foundation of China (grant No. 51508515) and the Science and Technology Innovation Activity Plan of Undergraduates in Zhejiang Province in China (grant No. 2018R412044). We thank Dr. Trudi Semeniuk from Liwen Bianji, Edanz Editing China (www.liwenbianji.cn/ac), for editing the English text of a draft of this manuscript.

\section{Conflict of Interest}

The authors declare no conflict of interest.

\section{References}

1. HU Y.J., LIN J., ZHANG S.Q., KONG L.D., FU H.B., CHEN J.M. Identification of the typical metal particles among haze, fog, and clear episodes in the Beijing atmosphere. Science of the Total Environment, 511, 369, 2015.

2. CHENG Z., WANG S.X., JIANG J.K., FU Q.Y., CHEN C.H., XU B.Y., YU J.Q., FU X., HAO J.M. Long-term trend of haze pollution and impact of particulate matter in the Yangtze River Delta, China. Environmental Pollution, 182, 101, 2013.

3. WU D., ZHANG F., LOU W.H., LI D., CHEN J.M. Chemical characterization and toxicity assessment of fine particulate matters emitted from the combustion of petrol and diesel fuels. Science of the Total Environment, 605606, 172, 2017.

4. JANSSEN N.A.H., VAN MANSOM D.F.M., VAN DER JAGT K., HARSSEMA H., HOEK G. Mass concentration and elemental composition of airborne particulate matter at street and background locations. Atmospheric Environment, 31 (8), 1185, 1997.

5. HENNIG F., FUKS K., MOEBUS S., WEINMAYR G., MEMMESHEIMER M., JAKOBS H., BRÖCKERPREUSS M., FÜHRER-SAKEL D., MÖHLENKAMP S., ERBEL R., JÖCKEL K.H., HOFFMANN B., HEINZ NIXDORF RECALL STUDY INVESTIGATIVE GROUP. Association between source-specific particulate matter air pollution and hs-CRP: Local traffic and industrial emissions. Environmental Health Perspectives, 122 (7), 703, 2014.

6. AYDIN Y.M., KARA M., DUMANOGLU Y., ODABASI M., ELBIR T. Source apportionment of polycyclic aromatic hydrocarbons (PAHs) and polychlorinated biphenyls (PCBs) in ambient air of an industrial region in Turkey. Atmospheric Environment, 97, 271, 2014.

7. VANASSE A., TALBOT D., CHEBANA F., BÉLANGER D., BLAIS C., GAMACHE P., GIROUX J.X., DAULT R., GOSSELIIN P. Effects of climate and fine particulate matter on hospitalizations and deaths for heart failure in elderly: A population-based cohort study. Environment International, 106, 257, 2017.

8. YITSHAK-SADE M., KLOOG I., NOVACK V. Do air pollution and neighborhood greenness exposures improve the predicted cardiovascular risk? Environment International, 107, 147, 2017.

9. BARIMA Y.S.S., ANGAMAN D.M., N'GOURAN K.P., KOFFI N.A., TRA BI F.Z., SAMSON R. Involvement of leaf characteristics and wettability in retaining air matter from tropical plant species. Environmental Engineering Research, 21 (2), 121, 2016.

10. LEONARD R.J., MC ARTHUR C., HOCHULI D.F. Particulate matter deposition on roadside plants and the importance of leaf trait combinations. Urban Forestry \& Urban Greening, 20, 249, 2016.

11. SHAO F., WANG L.H., SUN F.B., LI G., YU L., WANG Y.J., ZENG X.R., YAN H., DONG L., BAO Z.Y. Study on different particulate matter retention capacities of the leaf surfaces of eight common garden plants in Hangzhou, China. Science of the Total Environment, 652, 939, 2019.

12. DZIERŻANOWSKI K., POPEK R., GAWROŃSKA H., SÆBØ A., GAWROŃSKI S.W. Deposition of particulate matter of different size fractions on leaf surfaces and in waxes of urban forest species. International Journal of Phytoremediation, 13 (10), 1037, 2011.

13. ZHAO S.T., LI X.Y., LI Y.M. Fine Particle-retaining capability of twenty-nine landscape plant species in Beijing. Ecology and Environmental Sciences, 24 (6), 1004, 2015.

14. TERZAGHI E., WILD E., ZACCHELLO G., CERABOLINI B.E.L., JONES K.C., DI GUARDO A. Forest Filter Effect: Role of leaves in capturing/ releasing air particulate matter and its associated PAHs. Atmospheric Environment, 74, 378, 2013. 
15. YANG H.Y., GUO J.P., LU S.Y., BI B., CAO F.M., JIA J.M. Effects of plants harvesting on polycyclic aromatic hydrocarbons removal of constructed wetland. China Environmental Science, 36 (5), 1554, 2016.

16. HOFMAN J., BARTHOLOMEUS H., JANSSEN S., CALDERS K., WUYTS K., WITTENBERGHE S.V., SAMSON R. Influence of tree crown characteristics on the local $\mathrm{PM}_{10}$ distribution inside an urban street canyon in Antwerp (Belgium): A model and experimental approach. Urban Forestry \& Urban Greening, 20, 265, 2016.

17. BECKETT K.P., FREER-SMITH P., TAYLOR G. Effective tree species for local air quality management. Journal of Arboriculture, 26 (1), 12, 2000.

18. LI C.Y., CUI L.J., ZHANG X.D., ZHU Y.N., LI W., LEI Y.R. KANG X.M. Particulate matter adsorption capacity of 7 species of wetland plants in Beijing. Ecology and Environmental Sciences, 25 (12), 1967, 2016.

19. NOWAK D.J., CRANE D.E., STEVENS J.C. Air pollution removal by urban trees and shrubs in the United States. Urban Forestry \& Urban Greening, 4, 115, 2006.

20. ZHANG W.K., WANG B., NIU X. Study on the adsorption capacities for airborne particulates of landscape plants in different polluted regions in Beijing (China). International Journal of Environmental Research and Public Health, 12 (8), 9623, 2015.

21. LIU L., FANG Y.M., WANG S.C., XIE Y., YANG D.D. Leaf micro-morphology and features in adsorbing air suspended particulate matter and accumulating heavy metals in seven trees species. Environmental Science, $\mathbf{3 4}$ (6), 2361, 2013.

22. ZHANG W.K., WANG B., NIU X. Relationship between leaf surface characteristics and particle capturing capacities of different tree species in Beijing. Forests, 8 (3), 92, 2017.

23. SÆBØ A., POPEK R., NAWROT B., HANSLIN H.M., GAWRONSKA H., GAWRONSKI S.W. Plant species differences in particulate matter accumulation on leaf surfaces. Science of the Total Environment, 427-428, 347, 2012.

24. SONG Y.S., MAHER B.A., LI F., WANG X.K., SUN X., ZHANG H.X. Particulate matter deposited on leaf of five evergreen species in Beijing, China: Source identification and size distribution. Atmospheric Environment, 105, 53, 2015.
25. YAN J.L., LIN L., ZHOU W.Q., HAN L.J., MA K.M. Quantifying the characteristics of particulate matters captured by urban plants using an automatic approach. Journal of Environmental Sciences, 39, 259, 2016.

26. PRZYBYSZ A., SÆBØ A., HANSLIN H.M., GAWROŃSKI S.W. Accumulation of particulate matter and trace elements on vegetation as affected by pollution level, rainfall and the passage of time. Science of the Total Environment, 481, 360, 2014.

27. TAI A.P.K., MICKLEY L.J., JACOB D.J. Correlations between fine particulate matter $\left(\mathrm{PM}_{2.5}\right)$ and meteorological variables in the United States: Implications for the sensitivity of $\mathrm{PM}_{2.5}$ to climate change. Atmospheric Environment, 44, 3976, 2010.

28. XIE B.Z., WANG H.X., YANG J., WANG Y.H., SHI H. Retention capability of $\mathrm{PM}_{2.5}$ and its explanation by leaf surface micro-structure of common broad-leaved plant species in Beijing. Acta Botanica Boreali-Occidentalia Sinica, 34 (12), 2432, 2014.

29. WANG F., XIONG S.G., LI H.Y., LI L.L., ZHANG Q.M., HE M.X. Study on dust-retention ability of major afforestation tree species in Tianjin airport economic area. Journal of Arid Land Resources and Environment, 29 (1), 100, 2015.

30. ZHANG J.Y., ZHOU J.L., REN M., HU H.B. Comparison of dust retention capacities by 20 urban road afforestation trees. Journal of Northwest Normal University (Natural Science), 49 (5), 113, 2013.

31. GAO C.Y. Research on dust retention capacities and physiological properties of different typical green plants in Nanning city. Research of Soil and Water Conservation, 23 (1), 187, 2016.

32. WANG H.X., SHI H., LI Y.Y., YU Y., ZHANG J. Seasonal variations in leaf capturing of particulate matter, surface wettability and micromorphology in urban tree species. Frontiers of Environmental Science \& Engineering, 7 (4), 579, 2013.

33. FANG Y., ZHANG J.C., WANG Y.H. Dustfall adsorbing capacity of major species of greening trees in Nanjing and its law. Journal of Ecology and Rural Environment, 23 (2), 36, 2007. 
